\title{
Pregnant dairy goats endoparasites reduced by commercial populational Homeopathy
}

\author{
Ana Luiza Ribeiro Almeidaํㅗ Ana Gabriela Barros e Silva1, \\ Ester Beghini Lacerda ${ }^{1}$, Nathalye Vasconcellos de Almeida Rezende \\ Machado $^{1}$, Angelo Liparini Pereira ${ }^{1}$, Silvio Leite Monteiro da Silva ${ }^{1,2}$
}

(1) IF Sudeste MG campus Rio Pomba, Minas Gerais, Brazil;

(2) Research Center, Universidade Paulista (UNIP), São Paulo, Brazil

Background: the dairy goats are affected by a world distribution endoparasitosis. This affects the economical activity and implies in eminent risk of animal looses by helminths blood depletion. Resistance to all therapeutic drugs is reported, the parasitism implies to elevation of production costs, toxic residues in milk and environment, frequently monitoring of ocular mucosa and healthy status. Many publications relates FEC reductions in sheeps with homeopathy (Chagas, 2008; Zacharias 2008; Neves, 2012; Falbo, 2013). This work continues the study of previous assessment with young females caprines, but now during the breeding season and pregnant multipara. The under field conditions intends to determine the value of this complex medicine in the real life situation of a caprinoculture routine and the animal zootechnical production phases. Aims: this work determined the parasite load by Fecal Eggs Count (FEC) during the periods of breeding season and pregnancy of dairy goats with commercial populational homeopathy. Methodology: Fifteen (15) adult multipara goats (Capra aegagrus hircus) aged $4.4 \pm 1.4$ years old were divided into two groups by the odd or even last number of registry given in the birth. The animals has dairy predominance of Alpine and Saanen breeds and were fed by maize and sugar cane silage. Routine measures to reduce the natural parasitism infection included to keep them in elevated houses with slatted floor with acess to paddock star grass with time restrictions to the hottest hours in the day. They received the albendazole antihelmintic drenching before each of the phases. The weekly FEC was made in triplicate with the McMaster Egg Counting Technique. The treatment with 10g-animal-day CapriOvi Verm 100 RealH (Brazil) was continuously given daily among both phases, six times by week with individual oral administration, the powder was diluted (not sucussed) in a plastic cup with tap water and given with a $10 \mathrm{~mL}$ syringe. The control group received only tap water in the same way but brand new separated set of disposable materials. The two phases had ten weeks of evaluating period. The first phase has the four weeks breeding season previously stimulated by light program with sex mating in the middle and the second phase the animals was pregnant for 2 to 4 months. Results: The FEC was significantly reduced during the pregnancy- $2^{\text {nd }}$ phase $(p$-value $<0,01)$ but not in the breeding season- $1^{\text {st }}$ phase ( $\mathrm{p}$-value $=0,28)$. The two-way ANOVA showed that the treatment in the $2^{\text {nd }}$ phase affected the results $[\mathrm{F} 1 / 143=9.04, \mathrm{p}=0.0031]$ as the time does $[\mathrm{F} 1 / 143=53,29, \mathrm{p}<0.0001]$ : there were interactions between the factors $[\mathrm{F} 1 / 143=3.15, \mathrm{p}=0.0011]$. The two-way ANOVA showed that the treatment in the $1^{\text {nd }}$ phase affected the results $[\mathrm{F} 1 / 130=0.30, \mathrm{p}=0.58]$ as the time does $[\mathrm{F} 1 / 130=1.24, \mathrm{p}=0.28]$ : there were no interactions between the factors $[F 1 / 130=0.58, p=0.81]$. The mechanism that increases the medicine effect may have interaction to the time or to the stress condition of pregnancy. We suppose that the stressed animal model may exacerbate the expected effect more than the time effect, as both were present in the $2^{\text {nd }}$ phase. How its influences the way of action of the ultra high dilutions remains a very interesting question for guide future 
works. Conclusion: the populational homeopathy product CapriOvi Verm 100 RealH has show the reduction of the FEC during the pregnancy of dairy goats.

Keywords: Goats, Fecal Eggs Count, endoparasite, caprinoculture, populational homeopathy

\section{(c)) BY-NC-ND Licensed to GIRI}

Support: Fundação de Apoio ao Ensino, Pesquisa e Extensão Deputado Ultimo de Carvalho (FADUC) for fellowship, Real H Nutrição e Saúde Animal for general support, Federal Institute of Education, Science and Technology from Southeast of Minas Gerais (IF Sudeste MG), Rio Pomba campus for general support.

Conflict of interest: authors declare there is no conflict of interest

Received: March 30 ${ }^{\text {th }} 2014$; Revised:May 10 ${ }^{\text {th }} 2014$; Published: June $30^{\text {th }} 2014$.

Correspondence author: Ana Luiza Ribeiro Almeida, analusbt@hotmail.com

How to cite this article: Almeida ALR, Silva AGB, Machado NVAR, Lacerda EB, Pereira AL, Monteiro da Silva SL. Pregnant dairy goats endoparasites reduced by commercial populational homeopathy. Int J High Dilution Res [online]. 2014 [cited YYYY Month dd]; 13(47):135-136. Proceedings of the XXVIII GIRI Symposium; 2014 Jun20-22; Sighisoara (Romania). GIRI; 2014; Available from: http://www.feg.unesp.br/ ojs/index.php/ijhdr/article/view/742/717 